\title{
Identification and characterization of genes frequently responsive to Xanthomonas oryzae pv. oryzae and Magnaporthe oryzae infections in rice
}

\author{
Weiwen Kong ${ }^{1,2^{*}}$ (D) Li Ding ${ }^{1}$ and Xue Xia ${ }^{1}$
}

\begin{abstract}
Background: Disease resistance is an important factor that impacts rice production. However, the mechanisms underlying rice disease resistance remain to be elucidated.

Results: Here, we show that a robust set of genes has been defined in rice response to the infections of Xanthomonas oryzae pv. oryzae (Xoo) and Magnaporthe oryzae (Mor). We conducted a comprehensive analysis of the available microarray data from a variety of rice samples with inoculation of Xoo and Mor. A set of 12,932 genes was identified to be regulated by $X_{0 O}$ and another set of 2709 Mor-regulated genes was determined. GO enrichment analysis of the regulated genes by Xoo or Mor suggested mitochondrion may be an arena for the up-regulated genes and chloroplast be another for the down-regulated genes by Xoo or Mor. Cytokinin-related processes were most frequently repressed by XoO, while processes relevant to jasmonic acid and abscisic acid were most frequently activated by Xoo and Mor. Among genes responsive to $X_{0 O}$ and Mor, defense responses and diverse signaling pathways were the most frequently enriched resistance mechanisms. InterPro annotation showed the zinc finger domain family, WRKY proteins, and Myb domain proteins were the most significant transcription factors regulated by Xoo and Mor. KEGG analysis demonstrated pathways including 'phenylpropanoid biosynthesis', 'biosynthesis of antibiotics', 'phenylalanine metabolism', and 'biosynthesis of secondary metabolites' were most frequently triggered by Xoo and Mor, whereas 'circadian rhythmplant' was the most frequent pathway repressed by Xoo and Mor.

Conclusions: The genes identified here represent a robust set of genes responsive to the infections of Xoo and Mor, which provides an overview of transcriptional reprogramming during rice defense against $X_{0 O}$ and Mor infections. Our study would be helpful in understanding the mechanisms of rice disease resistance.
\end{abstract}

Keywords: Rice, Xanthomonas oryzae pv. oryzae, Magnaporthe oryzae, Transcriptome, Disease resistance, Disease susceptibility

\section{Background}

Rice is one of the most staple food crops. During their entire growth, rice plants are capable of perceiving the invasion of a large number of micro-organisms, such as fungi, bacteria, and viruses. It has been established that plants are able to recognize and respond to various kinds of

\footnotetext{
* Correspondence: wwkong@yzu.edu.cn

'School of Horticulture and Plant Protection, Yangzhou University, Yangzhou 225009, Jiangsu, China

${ }^{2}$ Joint International Research Laboratory of Agriculture and Agri-Product Safety of the Ministry of Education, Yangzhou University, Yangzhou 225009, Jiangsu, China
}

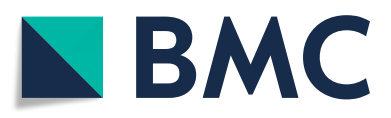

(c) The Author(s). 2020 Open Access This article is distributed under the terms of the Creative Commons Attribution 4.0 International License (http://creativecommons.org/licenses/by/4.0/), which permits unrestricted use, distribution, and reproduction in any medium, provided you give appropriate credit to the original author(s) and the source, provide a link to the Creative Commons license, and indicate if changes were made. The Creative Commons Public Domain Dedication waiver (http://creativecommons.org/publicdomain/zero/1.0/) applies to the data made available in this article, unless otherwise stated.

pathogens through their complex innate immunity systems $[1,2]$. In the long-term struggle for survival, plants have evolved two lines of defense to pathogens, i.e., pathogenassociated molecular pattern (PAMP)-triggered immunity (PTI) and effector-triggered immunity (ETI) [3-5]. PTI could be activated by some extracellular, transmembrane receptors, also named pattern recognition receptors (PRRs) to suppress pathogen invasions. PRRs function in recognizing conserved PAMPs. The induction of ETI is the result of the recognition of pathogen avirulence effectors through disease resistance proteins of a host. During ETI response, 
hypersensitive reaction (HR), a specific programmed cell death (PCD), is often observed in plants. Many components have been demonstrated essential in the PTI and ETI processes in Arabidopsis thaliana [2, 6, 7].

Bacterial leaf blight is the most significant bacterial disease of rice. Its causal agent Xanthomonas oryzae pv. oryzae $(X o o)$, is a member of the gamma subdivision of the proteobacteria. Another popular rice disease is known as rice blast, which is caused by a filamentous ascomycete fungus, named Magnaporthe oryzae (Mor). Although disease resistance in rice has been extensively studied, there is still a little knowledge of the rice response to pathogen infections. It has been demonstrated that the invasions of Xoo and Mor on rice plants are mainly mediated through altering rice gene expression at the transcriptional level [8-11]. Hence, uncovering the transcriptional changes of rice genes during the infections of $\mathrm{Xoo}$ and Mor is of particular significance.

In rice plants, PTI and ETI were observed in response to Xoo [12] and Mor infection [13, 14]. Extensive researches have revealed that some phytohormones, e.g., jasmonic acid (JA), abscisic acid (ABA), salicylic acid (SA), and ethylene (ET), are important in the rice responses to Xoo [15-20] and Mor infections [21-23].

Up to date, plenty of microarray data of rice infected by $\mathrm{Xoo}$ and Mor have been produced, and these data give an opportunity to elucidate the mechanisms of rice response to the infections of the two pathogens. Previous microarray-based studies, however, focused on only a limited of samples. Although numerous rice genes responsive to Xoo and Mor infections have been identified, which led to insights into the rice resistance/susceptibility mechanisms, similar or specific results were usually obtained in different studies for the sake of specific experimental conditions.

The aim of this study is to determine a robust set of rice genes in response to Xoo and Mor infections, defining genes that are frequently regulated in diverse conditions through analysis of the publicly available rice microarray data sets associated with the infections of Xoo and Mor. To find out which mechanisms may be more common in rice response to the infections by these two pathogens, the gene sets determined were next analyzed for enrichment of Gene Ontology (GO) terms and KEGG (Kyoto Encyclopedia of Genes and Genomes) pathways. Furthermore, the distributions of the significant enrichment of the GO and KEGG as well as the InterPro annotation were investigated.

\section{Results}

Identification of genes responsive to Xoo and Mor infections in the rice microarray data

We employed 69 pairs (including control and treatment) of microarray samples (consisting of 51 pairs of Xoo- infected samples and 18 pairs of Mor-infected samples) from 15 series of experiments to query Xoo- and Mor-induced gene expression changes, all of which were conducted by the use of the Affymetrix rice wholegenome arrays platform (GPL2025) (Additional file 4: Table S1). The data from the same platform were retrieved for the analysis to avoid the variance of different platforms, and the GEO2R tool was used to process all the samples uniformly to eliminate the technical variance of data transformation. Moreover, poor quality arrays with no match or matching multiple loci were discarded. Further, we only considered the samples with no less than 989 differentially expressed genes (DEGs) $(P \leq 0.05)$. In the end, we identified the DEGs from 29 pairs of Xoo-infected samples and 6 pairs of Mor-infected samples (Additional file 5: Table S2). The number of DEGs in these samples varied from 989 to 9769 genes (Additional file 5: Table S2). Totally, 12,932 DEGs (occurring at least three pairs of array samples) were identified in the Xoo-infected rice microarray data (Table 1). Of the DEGs, 7452 genes were up-regulated and 5480 genes were down-regulated (Table 1). Also, 2709 DEGs (occurring at least three pairs of array samples) were identified in the Mor-infected rice microarray data (Table 1). Out of these genes, 1615 were upregulated and 1094 were down-regulated by Mor (Table 1).

Comparing the two groups of the identified DEGs, we found that 11,075 genes were expressed differentially in common between Xoo- and Mor- infected rice array samples, with 5580 DEGs being up-regulated and 5495 DEGs being down-regulated (Fig. 1). If only considering the DEGs that were present in at least three pairs of samples infected by Xoo or in at least two pairs of samples infected by Mor, it could be found that 3831 DEGs were shared by Xoo- and Mor- infected array samples, with 2140 DEGs being up-regulated and 1691 DEGs being down-regulated (Additional file 1: Figure S1).

In a previous study, we showed that 882 rice genes contain pathogen-inducible cis-regulatory elements (PICEs) in their promoter regions [24]. Here we found that 389 DEGs contain the PICEs in their promoters (Additional file 3: Table S3). There is a $3.51 \%(389 / 11075)$ overlap or a $44.1 \%$ (389/882) overlap between the DEGs and the genes with PICEs in the promoters. And among the above 3831 DEGs, 304 genes were found to be overlapped with the prior set of genes carrying the PICEs in their promoters, which account for 7.93\% of the DEGs (Additional file 7: Table S4). It seems that the PICEs in the promoters make genes accessible to be frequently regulated by pathogens.

GO enrichment analysis of the DEGs in the Xoo- and Morinfected rice samples

GO enrichment analysis provides some detailed information on the potential functions of genes. However, the 
Table 1 The number of differentially expressed genes identified in the rice microarray data with inoculation of Xoo and Mor

\begin{tabular}{|c|c|c|}
\hline $\begin{array}{l}\text { Number of } \\
\text { sample }\end{array}$ & $\begin{array}{l}\text { Number of } \\
\text { up-reg gene }\end{array}$ & $\begin{array}{l}\text { Number of } \\
\text { down-reg gene }\end{array}$ \\
\hline \multicolumn{3}{|c|}{ Inoculation with $X_{O O}$} \\
\hline 22 & 1 & 0 \\
\hline 21 & 1 & 1 \\
\hline 20 & 2 & 1 \\
\hline 19 & 4 & 3 \\
\hline 18 & 9 & 9 \\
\hline 17 & 20 & 24 \\
\hline 16 & 40 & 38 \\
\hline 15 & 85 & 74 \\
\hline 14 & 180 & 156 \\
\hline 13 & 318 & 264 \\
\hline 12 & 561 & 422 \\
\hline 11 & 850 & 644 \\
\hline 10 & 1209 & 925 \\
\hline 9 & 1598 & 1256 \\
\hline 8 & 2118 & 1657 \\
\hline 7 & 2759 & 2125 \\
\hline 6 & 3562 & 2702 \\
\hline 5 & 4567 & 3411 \\
\hline 4 & 5969 & 4297 \\
\hline 3 & 7452 & 5480 \\
\hline 2 & 9360 & 7445 \\
\hline 1 & 12,062 & 10,372 \\
\hline \multicolumn{3}{|c|}{ Inoculation with Mor } \\
\hline 6 & 15 & 0 \\
\hline 5 & 179 & 10 \\
\hline 4 & 640 & 145 \\
\hline 3 & 1615 & 1094 \\
\hline 2 & 3210 & 3830 \\
\hline 1 & 6928 & 8389 \\
\hline
\end{tabular}

up-reg up-regulated, down-reg down-regulated existing GO terms are too disorganized to succinctly describe the functional information of a large set of genes. Here, combining the routine GO terms, we tentatively use more broad terms to describe the $\mathrm{GO}$ enrichment results of the DEGs in the Xoo- and Mor-infected rice samples. GO enrichment analysis revealed that ribosome, snRNP complex and spliceosome, and diverse membranes were the most frequent cellular components in the up-regulated genes by Xoo (Fig. 2a and Additional file 8: Table S5). In contrast, chloroplast, membrane, and ribosome were the most frequent cellular components in the down-regulated genes by Xoo (Fig. 2a and Additional file 9: Table S6).

GO enrichment results also demonstrated that the most frequent biological processes were: (1) rRNA maturation, processing, and modification; (2) transcription, post-transcription regulation; (3) translation, posttranslation regulation, and (4) defense response in the up-regulated genes by Xoo (Fig. 2a and Additional file 10: Table S7). In the down-regulated genes by Xoo, the most frequently enriched biological processes were: (1) chloroplast organization and photosynthesis; (2) carbohydrate biosynthesis, transport and metabolism; (3) translation, post-translational regulation; and (4) transport (Fig. 2a and Additional file 11: Table S8).

Analysis on the molecular functions of the genes induced by Xoo showed that RNA binding, defense enzymes and other enzymes were significantly enriched in the up-regulated genes (Fig. 2a and Additional file 12: Table S9). By contrast, defense enzymes and other enzymes, as well as transporters were the frequently enriched molecular function categories in the downregulated genes by Xoo (Fig. 2a and Additional file 13: Table S10).

In the up-regulated genes by Mor, the analysis presented that the most frequently enriched cellular components were membrane, mitochondrion, proteasome, and ribosome (Fig. 2b and Additional file 14: Table S11); whereas the most frequently enriched cellular components were chloroplast, snRNP complex and
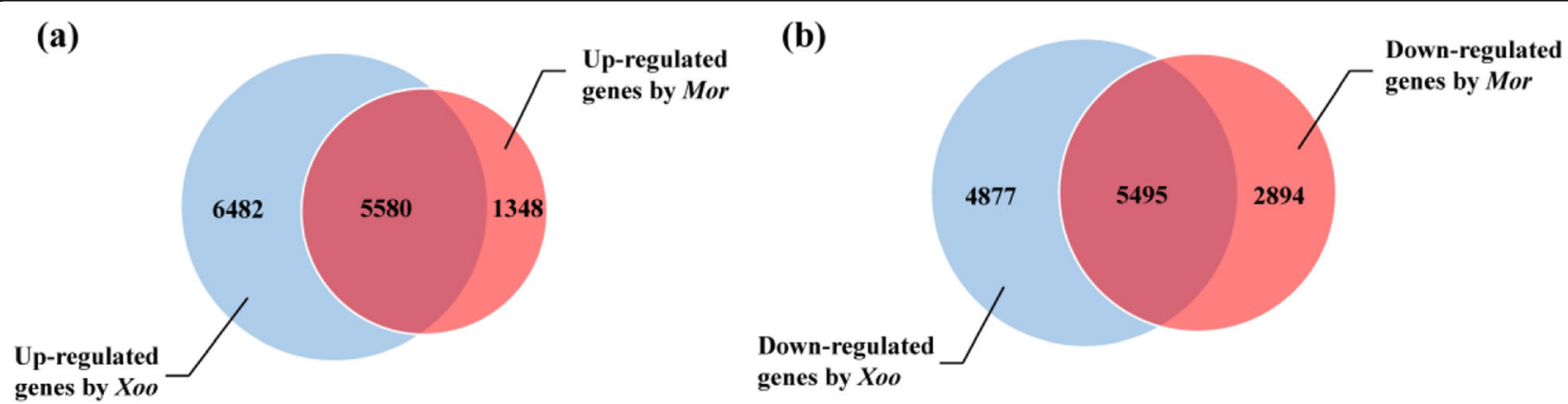

Fig. 1 Number of unique and common differentially expressed genes (DEGs) induced by Xoo and Mor in rice. a Up-regulated genes; b Down-regulated genes 


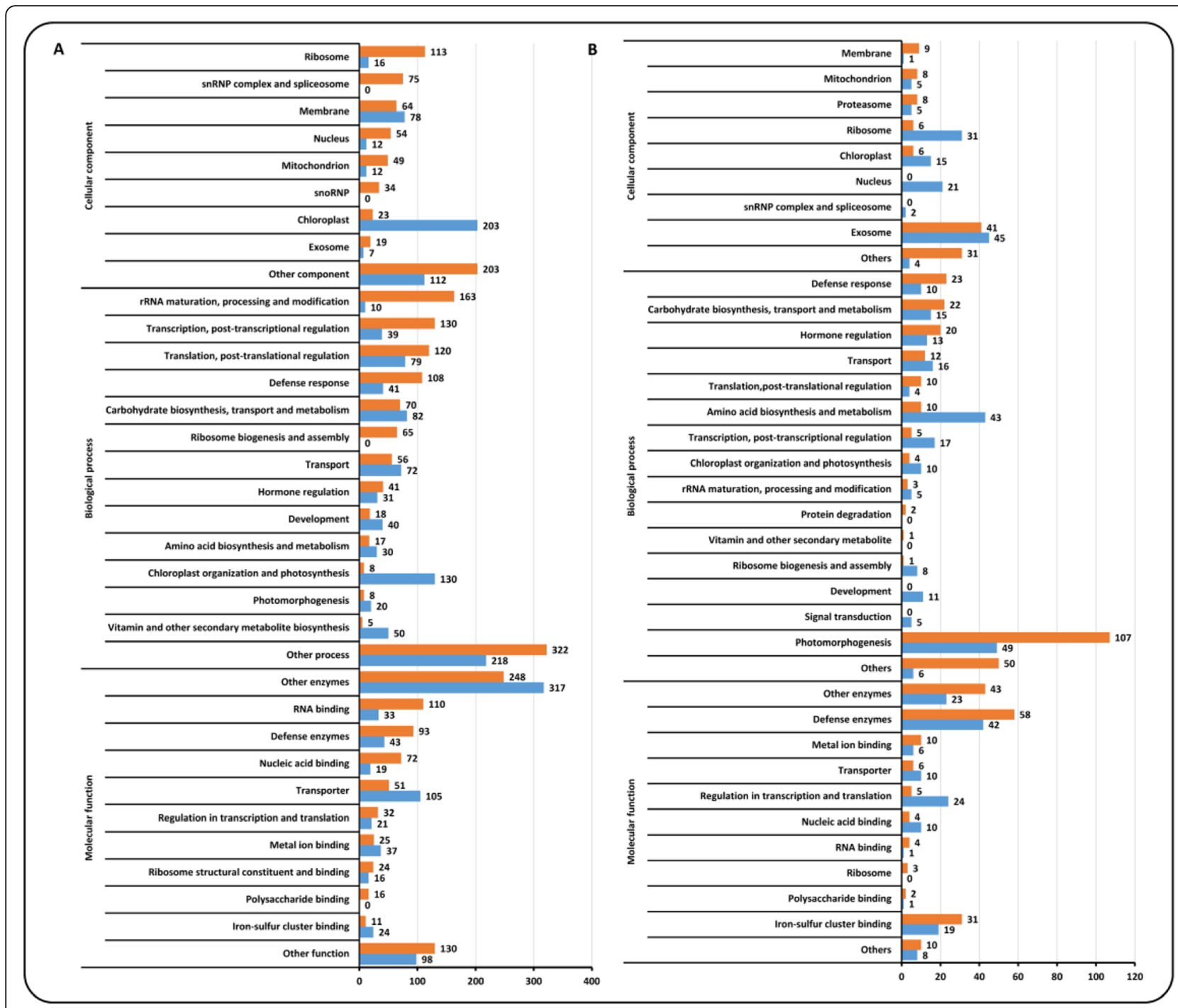

up-regulation down-regulation

Fig. 2 The distribution of the gene ontology annotation (GO) for the induced genes in the rice microarray data. a $\mathrm{GO}$ for the induced genes by Xoo; $\mathbf{b}$ GO for the induced genes by Mor

spliceosome, and nucleus in the genes down-regulated by Mor (Fig. 2b and Additional file 15: Table S12).

On the biological processes that the induced genes by Mor involved in, enrichment analysis indicated that defense response, carbohydrate biosynthesis, transport and metabolism, and hormone regulation were the most frequent processes present in the up-regulated genes (Fig. 2b and Additional file 16: Table S13); while transcription, post-transcriptional regulation, chloroplast and photosynthesis, and translation, post-translational regulation were the most frequent processes occurring in the down-regulated genes (Fig. $2 b$ and Additional file 17: Table S14).
Enrichment on the GO molecular functions of the regulated genes by Mor showed that defense enzymes, other enzymes, metal ion binding, and transporter were the most frequent categories in the up-regulated genes (Fig. 2b and Additional file 18: Table S15); while in the down-regulated genes, nucleic acid binding, defense enzymes and other enzymes were included in the most frequent molecular functions (Fig. $2 b$ and Additional file 19: Table S16).

It has been established that most hormones are important in regulating rice disease resistance. Thus, we investigated the biological processes related to diverse hormones, which were activated or repressed after the 
infections of Xoo and Mor. We observed that some biological processes relative to hormones included the regulation of hormone-mediated signaling pathways, hormone biosynthetic/metabolic processes, and response to hormone (Fig. 3). Among the hormones, jasmonic acid and abscisic acid were prominent for the processes related to them were most frequently activated after infections by Xoo and Mor (Fig. 3). It is worth noting that the processes related to cytokinin (GO:0009735 and GO: 0009736) were most frequently repressed after Xoo infection (Fig. 3a). In samples infected by Mor, the processes relative to diverse hormones consisting of abscisic acid, auxin, cytokinin, jasmonic acid, and ethylene were evenly repressed (Fig. 3b).

Comparison of the most frequently observed GO enrichment results of the induced genes by Xoo and Mor revealed some interesting phenomena. Ribosome, membrane, mitochondria, and chloroplast were frequently observed, suggesting they were important cellular components where many genes were induced during the infections of Xoo or Mor. However, the occurring frequencies were different between the up- and downregulated patterns (Fig. 5). For example, the mitochondrion was a cellular component where the occurring frequency was higher in the up-regulated genes than the down-regulated genes by Xoo and Mor (Fig. 2 and Fig. 5). Conversely, the occurring frequency of the chloroplast was higher in the down-regulated genes than the up-regulated genes by both of the pathogens (Fig. 2 and Fig. 5). Therefore, when rice plants are subject to Xoo and Mor infections, mitochondria and chloroplast will turn into two important arenas, with the former being the one for up-regulated genes and the latter being another for down-regulated genes. Also, among the biological processes, defense response and hormone regulation were observed to be commonly and frequently activated by these two pathogens through up-regulating some related genes; and chloroplast organization and photosynthesis, development, and photomorphogenesis were commonly and frequently repressed by the two pathogens through down-regulating the relevant genes (Fig. 2 and Fig. 5). Similarly, the molecular functions including defense enzymes, ribosome structural constituent and binding, and polysaccharide binding were commonly and frequently observed in the up-regulated genes by the two pathogens (Fig. 2 and Fig. 5).

In addition, some frequent $\mathrm{GO}$ enrichment results were observed to be specific (Fig. 5). For example,
A

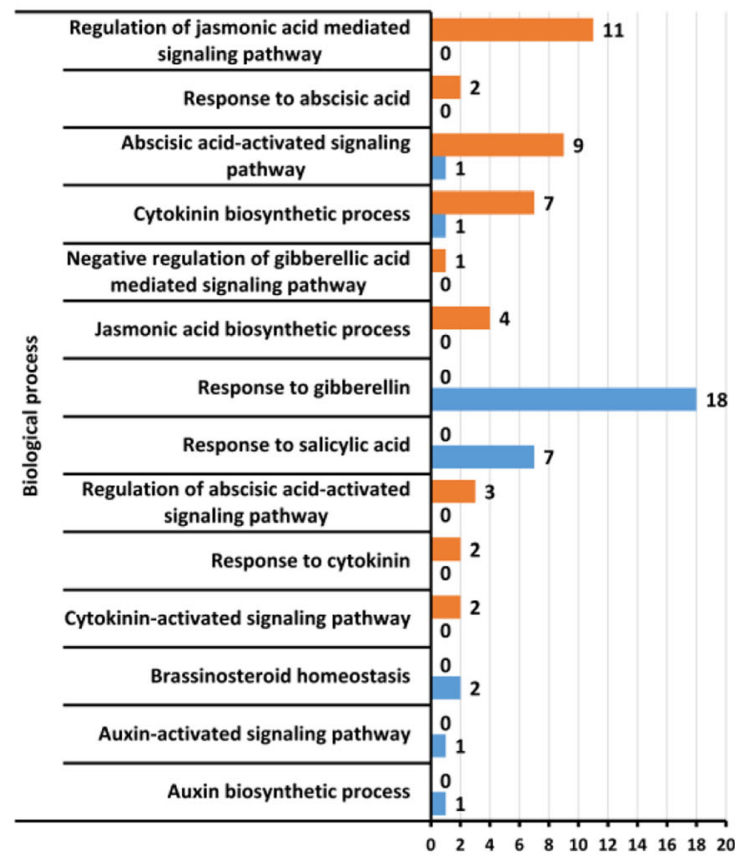

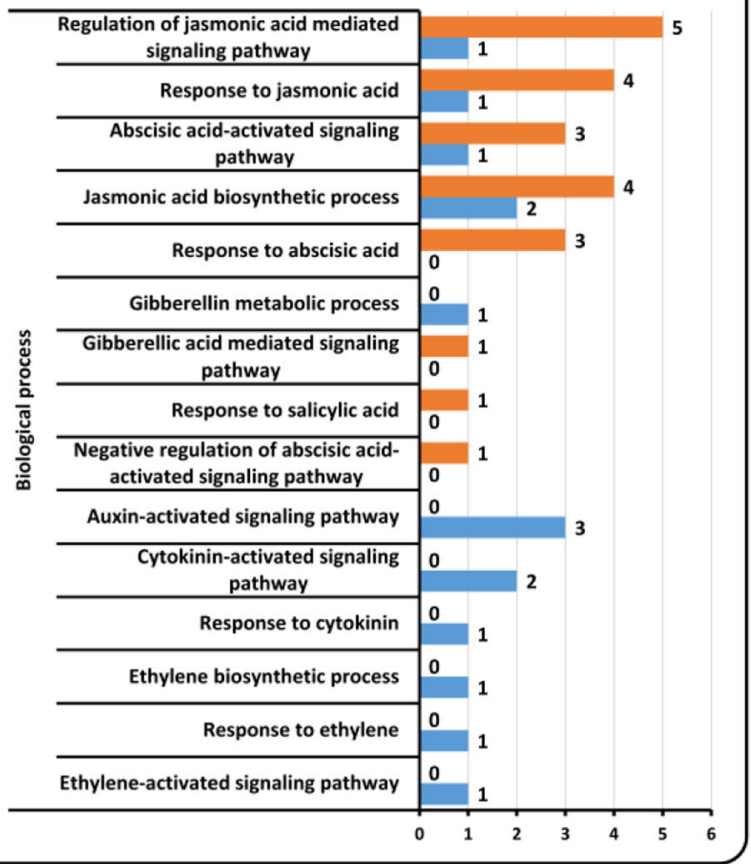

up-regulation down-regulation

Fig. 3 The distribution of the biological process (BP) relative to hormone regulation for the induced genes in the rice microarray data. a BP for the induced genes by XoO; $\mathbf{b}$ BP for the induced genes by Mor 
'snRNP complex and spliceosome' was only frequently occurring in the genes up-regulated by Xoo and downregulated by Mor; snoRNP was only frequently occurring in the up-regulated genes by Xoo (Fig. 2 and Fig. 5). The genes involved in ribosome biogenesis and assembly process were only frequently observed among the genes with an up-regulated pattern of expression induced by Xoo and Mor (Fig. 2 and Fig. 5). And the signal transduction process was only observed among the genes down-regulated by Mor (Fig. 2b and Fig. 5). The genes with polysaccharide binding function were exclusively identified in those with an up-regulated pattern of expression induced by the two pathogens (Fig. 2 and Fig. 5). Hence, some results obtained from the analysis of microarray data infected by Mor further supported that from the analysis of data infected by Xoo; on the other hand, comparison of the data infected by Mor to that by Xoo indicated that rice plants can use different mechanisms in response to their infections.

\section{Enriched InterPro annotation of the DEGs in rice induced by $\mathrm{Xoo}$ and Mor infections}

To further explore the possible functions of the DEGs in rice induced by $\mathrm{Xoo}$ and Mor infections, InterPro annotation enrichment analysis was conducted. The most frequent and significant InterPro annotations associated with the up-regulated DEGs by Xoo were diverse kinds of enzymes, e.g., dehydrogenase, synthase/synthetase, transferase, kinase, and glycoside hydrolase, followed by ribosomal proteins, translation proteins, and transcription factors; while among the down-regulated DEGs by Xoo, the most frequent and significant InterPro annotations were diverse enzymes including transferase, synthase/synthetase, reductase, dehydrogenase, and peptidase, etc., followed by transporter, transcription factors and ribosomal proteins (Table 2, Additional file 20: Table S17 and Additional file 21: S18).

In the up-regulated DEGs by Mor, the analysis showed that diverse kinds of enzymes (e.g., dehydrogenase, kinase, transferase, hydrolase, and synthase/ synthetase), transporters, and transcription factors were the top three enriched InterPro annotations; and in the down-regulated DEGs by Mor, it was demonstrated that various enzymes including kinase, transferase, synthase/synthetase, and so on, were annotated to be the most frequent products associated with the DEGs, followed by transcription factors, heat shock proteins and WD40 domain proteins (Table 3, Additional file 22: Table S19 and Additional file 23: Table S20.). Therefore, a number of enzymes were induced in rice response to Xoo and Mor infections, with some being up-regulated and others down-
Table 2 The distribution of the enriched INTERPRO annotations of the genes induced by $\mathrm{X}_{0 O}$ in the rice microarray data

\begin{tabular}{|c|c|c|}
\hline \multirow[t]{2}{*}{ Annotation } & \multicolumn{2}{|c|}{ Frequency in the analyzed samples } \\
\hline & Up-regulation & Down-regulation \\
\hline Enzyme & 1087 & 737 \\
\hline Dehydrogenase & 149 & 56 \\
\hline Synthase/synthetase & 123 & 124 \\
\hline Transferase & 122 & 137 \\
\hline Kinase & 87 & 32 \\
\hline Glycoside hydrolase & 79 & 28 \\
\hline ATPase & 60 & 15 \\
\hline Helicase & 48 & 10 \\
\hline Phosphatase & 48 & 13 \\
\hline Peptidase & 38 & 36 \\
\hline Reductase & 23 & 72 \\
\hline Peroxidase & 20 & 1 \\
\hline Lipoxygenase & 16 & 0 \\
\hline Other enzymes & 274 & 213 \\
\hline Ribosomal protein & 498 & 44 \\
\hline Translation protein & 88 & 3 \\
\hline Transcription factor & 68 & 63 \\
\hline Transporter & 62 & 128 \\
\hline WD40 & 39 & 0 \\
\hline Tubulin & 32 & 3 \\
\hline Heat shock protein & 26 & 8 \\
\hline Others & 972 & 842 \\
\hline
\end{tabular}

regulated. Among the enzymes, kinase, transferase, and synthase/synthetase were frequently activated or repressed during the rice response to Xoo and $\mathrm{Mor}$ infections. According to the above GO molecular function analysis of the DEGs, some activated enzymes belong to defense enzymes.

\section{Disease resistance/susceptibility-related (DRR/DSR) genes associated with $\mathrm{Xoo}$ and Mor infections in rice}

To identify the DRR/DSR genes, we performed a more detailed InterPro analysis on the Xoo- and Mor-regulated genes, combining with literature mining. Among the upregulated genes by $X o o$, the analysis indicated that genes from 106 InterPro annotated items were identified as DRR/DSR genes and the most frequently up-regulated genes by Xoo encode NAD(P)-binding domain proteins (IPR016040), which involve in reactive oxygen species (ROS) and SA signaling (Additional file 24: Table S21). Genes encoding chaperonin Cpn60/TCP-1 (IPR002423) and GroEL-like apical domain proteins (IPR027409) were also frequently activated, which are related to $\mathrm{PCD}$ and defense response, respectively (Additional file 24: Table S21). Among the down-regulated genes by Xoo, 
Table 3 The distribution of the enriched INTERPRO annotations of the up-regulated genes induced by Mor in the rice microarray data

\begin{tabular}{lll}
\hline Annotation & \multicolumn{2}{l}{ Frequency in the analyzed samples } \\
\cline { 2 - 3 } & Up-regulation & Down-regulation \\
\hline Enzyme & 382 & 143 \\
Dehydrogenase & 52 & 9 \\
Kinase & 50 & 18 \\
Transferase & 47 & 13 \\
Hydrolase & 34 & 8 \\
Synthase/synthetase & 33 & 11 \\
Peptidase & 18 & 9 \\
Reductase & 15 & 2 \\
ATPase & 12 & 3 \\
Lipoxygenase & 12 & 0 \\
Helicase & 8 & 10 \\
Phosphatase & 7 & 8 \\
Peroxidase & 1 & 1 \\
Other enzymes & 93 & 51 \\
Transporter & 34 & 5 \\
Transcription factor & 15 & 69 \\
Ribosomal protein & 8 & 7 \\
Heat shock protein & 5 & 8 \\
Translation protein & 3 & 3 \\
WD40 & 0 & 268 \\
Others & 209 & \\
\hline
\end{tabular}

the analysis showed that genes from 75 InterPro items were identified as DRR/DSR genes (Additional file 25: Table S22). Three groups of genes were most frequently down-regulated by Xoo, and they encode NAD(P)-binding domain proteins (IPR016040) (functioning in ROS and SA signaling), major facilitator superfamily (IPR020846 and IPR011701) (acting as defense proteins), and NAF/FISL domain proteins (IPR004041 and IPR018451) (involved in PTI), respectively (Additional file 25: Table S22).

Among genes responsive to Mor, the results demonstrated that genes from 39 InterPro annotated items were identified to be DRR/DSR genes, with up-regulated expression pattern (Additional file 26: Table S23). Interestingly, the most frequently activated genes by Mor also encode NAD(P)-binding domain proteins (IPR016040), and function in ROS and SA signaling (Additional file 26: Table S23). Among the downregulated genes by Mor, the putative DRR/DSR genes were confirmed to be distributed in 19 InterPro annotated items (Additional file 27: Table S24). Three groups of genes, which encode PB1 domain (Phox/Bem1p) proteins (IPR000270) (involved in defense response), DnaJ domain proteins (IPR001623) (implicated in cell death), and CCT domain proteins (IPR010402) (related to defense response), respectively, were most frequently repressed by Mor infection (Additional file 27: Table S24).

We further investigated the mechanisms on disease resistance of the identified DRR/DSR genes in rice response to Xoo and Mor infections through consulting a great number of papers. The results showed that various disease resistance mechanisms were conferred by the up-regulated genes by Xoo (Fig. 4a). For example, 29\% (264) of the up-regulated genes by Xoo played roles during defense responses or as defense proteins. One hundred ninety six genes $(22 \%)$ were probably involved in diverse signaling pathways, including SA, JA, ET, MAPK, receptor kinase and so on, among the up-regulated genes by Xoo. 12\% (105) of the up-regulated genes by Xoo were associated with PCD, HR or other cell death. A group of 101 up-regulated genes by Xoo (11\%) was related to basal and innate immunity including PTI, ETI. $7 \%$ (61) were implicated in ROS/oxidative stress, and 3\% (30) were found as transcription factors, among the upregulated genes by Xoo (Fig. 4a). A similar result was observed among the down-regulated genes by Xoo (Fig. 4b). For instance, $22 \%$ (161) of the down-regulated genes by $X o o$, the greatest group of genes, played a part in defense responses or as defense proteins. A group of 146 genes $(20 \%)$ was related to diverse signaling pathways mediated by SA, JA, ET, ABA, MAPK, and receptor kinase, among the down-regulated genes by Xoo. 10\% (76) of the down-regulated genes by Xoo were in association with PCD, HR and other cell death. 9\% (65) were involved in ROS, oxidative stress or antioxidant related protein. Another group of 51 down-regulated genes by Xoo (7\%) was implicated in basal and innate immunity including PTI, ETI. In addition, 48 down-regulated genes by Xoo $(6 \%)$ were present, which encoded transcription factors (Fig. 4b).

Analysis of the genes regulated by Mor revealed some disease resistance mechanisms (Additional file 1: Figure S1). Defense responses (49 genes, 27\%) were observed to be most frequently induced in rice after infection by Mor. A group of 32 genes (18\%) activated by Mor was implicated in signaling mediated by SA, ET, MAPK, etc. Some induced genes encoded antifungal proteins or were related to the synthesis of phytoalexin. Induced genes involving in PCD, HR and other cell death, and genes related to ROS accounted for $10 \%$ (19) and $8 \%$ (15), respectively (Additional file 2: Figure S2). Among the down-regulated genes by Mor, 54\% (27) encoded transcription factors; ten genes $(20 \%)$ were associated with cell death; four genes (8\%) were present in defense responses; additionally, several genes were related to auxin signaling, ethylene signaling, and NPR1 degradation, respectively (Additional file 3: Figure S3). 

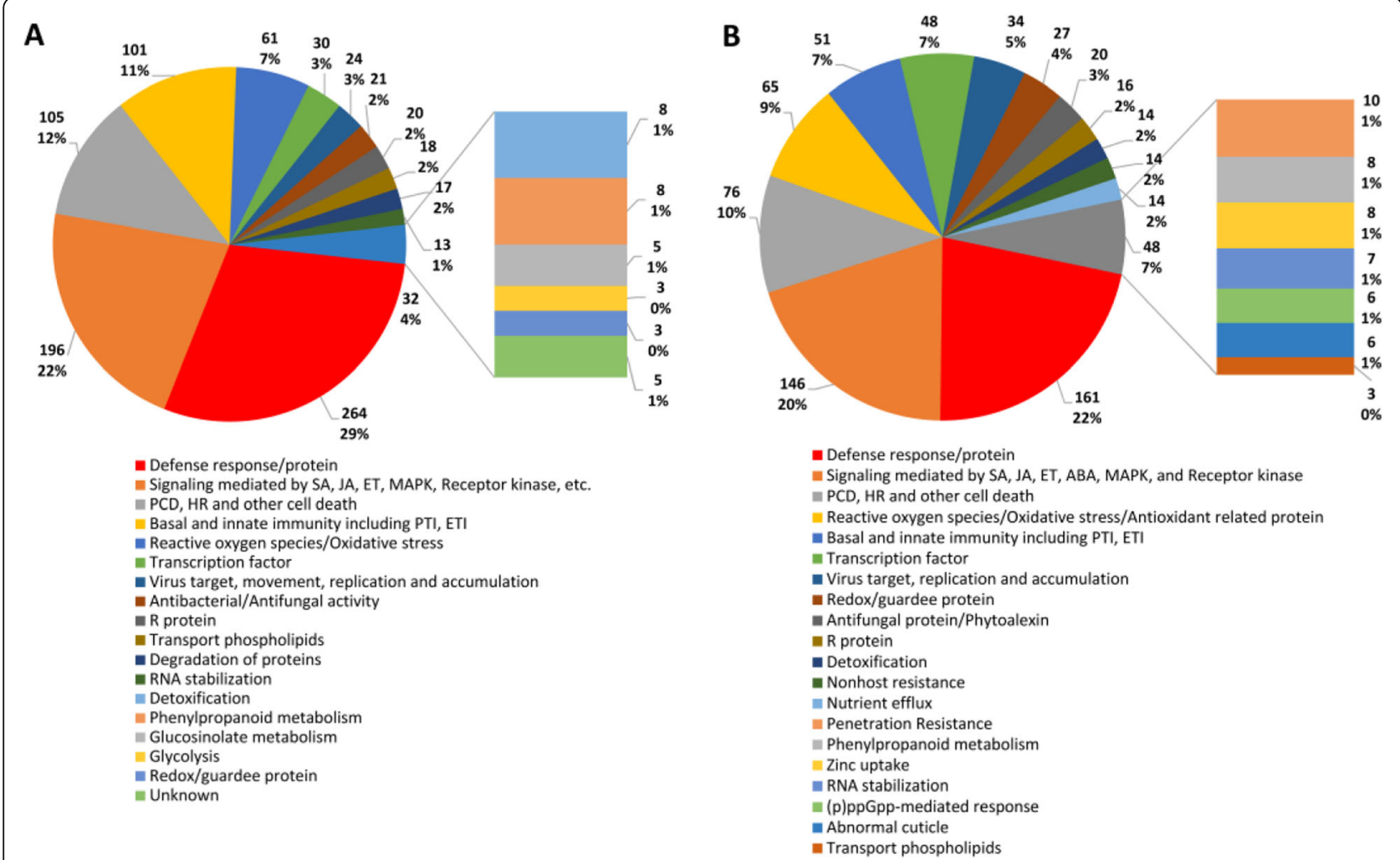

Fig. 4 Analysis on disease resistance mechanisms of the up-regulated DRR/DSR proteins in rice. a mechanism for the up-regulated proteins by Xoo; $\mathbf{b}$ mechanism for the up-regulated proteins by Mor

\section{Top regulated genes after Xoo and Mor infections}

We next determined the top regulated genes by Xoo and Mor in rice. We found that nine genes, which were occurring in at least 18 pairs of samples, were up-regulated after Xoo infection (Table 4). Os04g0650800, which encodes the D-3-phosphoglycerate dehydrogenase 3 in chloroplast, was found to be most frequently upregulated, with occurring in 22 pairs of Xoo-infected samples (Table 4). Four of the up-regulated genes are involved in defense responses (Os03g0235000, Os09g0 491772, Os08g0508800, and Os09g0484200) (Table 4). Another nine genes were observed to be frequently down-regulated by $\mathrm{Xoo}$, with happening in at least 18 pairs of samples (Table 5). Among the genes, one encodes the cinnamoyl-CoA reductase 1 (Os09g0491820), and was most frequently down-regulated by Xoo, with occurring in 21 pairs of samples; two genes (Os05g0204600 and Os06g0571800) encode different transcription factors (Table 5).

In Mor-infected samples, 16 genes were observed to be up-regulated in all the six pairs of samples analyzed (Table 6). Among these genes, five belong to defense genes (Os01g0713200, Os01g0963000, Os02g0569900, Os02g0570700, and Os10g0542900), one encodes a
WRKY transcription factor (Os01g0584900), and another gene (Os04g0647900) encodes an LRR receptor-like serine/threonine-protein kinase (Table 6). In the samples, ten genes were found to be down-regulated, with occurring in five pairs of samples (Table 7). Out of the genes, Os01g0719100 and Os03g0607700 encode two different zinc finger proteins, and Os09g0536400 encodes a defense protein (thaumatin-like protein 1b) (Table 7).

\section{Frequently observed transcription factors induced by Xoo and Mor in rice}

Transcription factors are pivotal components that regulate gene expression. Thus, we identified the differentially expressed transcription factors in the Xoo- and Mor-infected microarray data. InterPro annotation indicated that diverse zinc finger proteins were the most frequently observed among the up-regulated transcription factors in the Xoo-infected samples, and heat shock factors (IPR000232) were the second most frequently observed, followed by WRKY (IPR003657) and basicleucine zipper domain-containing proteins (IPR004827) (Additional file 8: Table S5). In the samples, zinc finger proteins were also the most frequently observed among the down-regulated transcription factors, whereas heat 
Table 4 Top 20 up-regulated genes in rice after Xoo infection

\begin{tabular}{|c|c|c|}
\hline Gene ID & Annotation & $\begin{array}{l}\text { Number of sample } \\
\text { infected by XoO } \\
(n=29)\end{array}$ \\
\hline Os04g0650800 & $\begin{array}{l}\text { D-3-phosphoglycerate } \\
\text { dehydrogenase 3, chloroplastic }\end{array}$ & 22 \\
\hline Os03g0235000 & peroxidase A2 & 20 \\
\hline Os08g0127100 & lysine histidine transporter 1 & 19 \\
\hline Os10g0444700 & $\begin{array}{l}\text { probable inorganic phosphate } \\
\text { transporter } 1-8\end{array}$ & 19 \\
\hline Os09g0491772 & $\begin{array}{l}\text { heat shock } 70 \mathrm{kDa} \text { protein, } \\
\text { mitochondrial }\end{array}$ & 18 \\
\hline Os08g0508800 & lipoxygenase 7, chloroplastic & 18 \\
\hline Os02g0720600 & $\begin{array}{l}\text { protein ASPARTIC PROTEASE IN } \\
\text { GUARD CELL } 1\end{array}$ & 18 \\
\hline Os09g0484200 & cytochrome c1 & 18 \\
\hline Os06g0150400 & uncharacterized LOC4340145 & 18 \\
\hline Os06g0547400 & peroxidase P7 & 17 \\
\hline Os09g0412400 & uncharacterized LOC4347040 & 17 \\
\hline Os12g0131100 & $\begin{array}{l}\text { glutamine--fructose-6-phosphate } \\
\text { aminotransferase [isomerizing] } 2\end{array}$ & 17 \\
\hline Os01g0830700 & $\begin{array}{l}\text { protein trichome birefringence- } \\
\text { like } 28\end{array}$ & 17 \\
\hline Os02g0627100 & phenylalanine ammonia-lyase & 17 \\
\hline Os03g0213100 & $\begin{array}{l}\text { protein transport protein Sec61 } \\
\text { subunit alpha }\end{array}$ & 17 \\
\hline Os11g0684000 & transcription factor MYB108 & 17 \\
\hline Os07g0550600 & benzyl alcohol O-benzoyltransferase & 17 \\
\hline Os01g0839300 & $50 S$ ribosomal protein $\mathrm{L} 17$ & 17 \\
\hline Os06g0116600 & $\begin{array}{l}\text { Proteinase inhibitor, propeptide } \\
\text { domain containing protein }\end{array}$ & 17 \\
\hline Os01g0217500 & protein DJ-1 homolog B & 17 \\
\hline
\end{tabular}

Table 5 Top 10 down-regulated genes in rice after Xoo infection

\begin{tabular}{lll}
\hline Gene ID & Annotation & $\begin{array}{l}\text { Number of sample } \\
\text { infected by XoO } \\
(n=29)\end{array}$ \\
\hline Os09g0491820 & cinnamoyl-CoA reductase 1 & 21 \\
Os05g0204600 & B-box zinc finger protein 22 & 19 \\
Os04g0532400 & salutaridine reductase & 19 \\
Os12g0124000 & $\begin{array}{l}\text { nuclear envelope pore } \\
\text { membrane protein POM 121 }\end{array}$ & 18 \\
Os01g0702000 & bifunctional nuclease 1 & 18 \\
Os06g0571800 & $\begin{array}{l}\text { putative GATA transcription } \\
\text { factor 22 }\end{array}$ & 18 \\
Os12g0529900 & $\begin{array}{l}\text { myosin heavy chain, striated } \\
\text { muscle }\end{array}$ & 18 \\
Os08g0480000 & $\begin{array}{l}\text { protein DETOXIFICATION 27 } \\
\text { Os04g0538100 }\end{array}$ & $\begin{array}{l}\text { elongation factor G-1, } \\
\text { chloroplastic }\end{array}$ \\
Os01g0763700 & $\begin{array}{l}\text { glycerophosphodiester } \\
\text { phosphodiesterase GDPD6 }\end{array}$ \\
\hline
\end{tabular}

Table 6 Top 16 up-regulated genes in rice after Mor infection

\begin{tabular}{|c|c|c|}
\hline Gene ID & Annotation & $\begin{array}{l}\text { Number of sample } \\
\text { infected by XoO } \\
(n=6)\end{array}$ \\
\hline Os01g0389200 & uncharacterized LOC4325227 & 6 \\
\hline Os01g0584900 & WRKY transcription factor SUSIBA2 & 6 \\
\hline Os01g0695800 & $\begin{array}{l}\text { ABC transporter B family } \\
\text { member } 11\end{array}$ & 6 \\
\hline Os01g0713200 & $\begin{array}{l}\text { glucan endo-1,3-beta-glucosidase } \\
\text { Gll }\end{array}$ & 6 \\
\hline Os01g0963000 & cationic peroxidase SPC4 & 6 \\
\hline Os02g0569900 & Cytochrome P450 family protein & 6 \\
\hline Os02g0570700 & Cytochrome P450 family protein & 6 \\
\hline Os04g0647900 & $\begin{array}{l}\text { LRR receptor-like serine/threonine- } \\
\text { protein kinase GSO1 }\end{array}$ & 6 \\
\hline Os06g0128800 & $\begin{array}{l}\text { C2 calcium/lipid-binding domain, } \\
\text { CaLB domain containing protein }\end{array}$ & 6 \\
\hline Os06g0226950 & $\begin{array}{l}\text { Fatty acid hydroxylase domain } \\
\text { containing protein }\end{array}$ & 6 \\
\hline Os06g0569500 & $\begin{array}{l}\text { ent-sandaracopimaradiene 3- } \\
\text { hydroxylase }\end{array}$ & 6 \\
\hline Os08g0137800 & $\begin{array}{l}\text { Cupredoxin domain containing } \\
\text { protein }\end{array}$ & 6 \\
\hline Os08g0189900 & germin-like protein 8-11 & 6 \\
\hline Os08g0190100 & germin-like protein 8-11 & 6 \\
\hline Os10g0542900 & chitinase 8 & 6 \\
\hline Os12g0555000 & $\begin{array}{l}\text { Similar to Probenazole-inducible } \\
\text { protein PBZ1 }\end{array}$ & 6 \\
\hline
\end{tabular}

Table 7 Top 10 down-regulated genes in rice after Mor infection

\begin{tabular}{lll}
\hline Gene ID & Annotation & $\begin{array}{l}\text { Number of sample } \\
\text { infected by Xoo } \\
(n=6)\end{array}$ \\
\hline Os07g0210000 & $\begin{array}{l}\text { exocyst complex component } \\
\text { EXO70B1 }\end{array}$ & 5 \\
Os01g0719100 & $\begin{array}{l}\text { RING zinc-finger protein, Stomata } \\
\text { opening }\end{array}$ & 5 \\
Os02g0732900 & APO protein 2, chloroplastic & 5 \\
Os01g0933600 & uncharacterized LOC9268621 & 5 \\
Os09g0479100 & $\begin{array}{l}\text { F-box domain, cyclin-like domain } \\
\text { containing protein }\end{array}$ & 5 \\
Os10g0465000 & WD repeat-containing protein 26 & 5 \\
Os07g0584900 & U-box domain-containing protein 4 & 5 \\
Os03g0607700 & $\begin{array}{l}\text { Zinc finger, C2H2-like domain con } \\
\text { taining protein. }\end{array}$ & 5 \\
Os08g0176100 & $\begin{array}{l}\text { phosphopantothenate--cysteine } \\
\text { ligase 2 }\end{array}$ & 5 \\
Os09g0536400 & thaumatin-like protein 1b & 5 \\
\hline
\end{tabular}


shock factors (IPR000232) and WRKY (IPR003657) were not observed (Additional file 28: Table S25). Instead, Myb domain proteins were the second most frequently observed in the down-regulated transcription factors in the Xoo-infected samples (Additional file 28: Table S25).

Of the up-regulated transcription factors in the Morinfected samples, the WRKY proteins (IPR003657) were the maximum of the induced transcription factors, followed by the Myb domain factors (IPR006447, IPR017930) (Additional file 29: Table S26). Among the down-regulated transcription factors in these samples, various kinds of zinc finger domain proteins were also the most frequently induced transcription factors, and the Myb domain proteins (IPR006447, IPR017930, and IPR001005) were the second frequently induced (Additional file 29: Table S26). Therefore, the zinc finger domain family, WRKY proteins, and Myb domain proteins were the most significant proteins among the differentially expressed transcription factors in most of the Xoo- and Mor-infected samples (Fig. 5).

\section{KEGG enrichment analysis of the DEGs induced by Xoo and Mor in rice}

To search the enriched pathways potentially targeted by the DEGs in rice induced by Xoo and Mor infections, KEGG annotation was performed. The analysis indicated

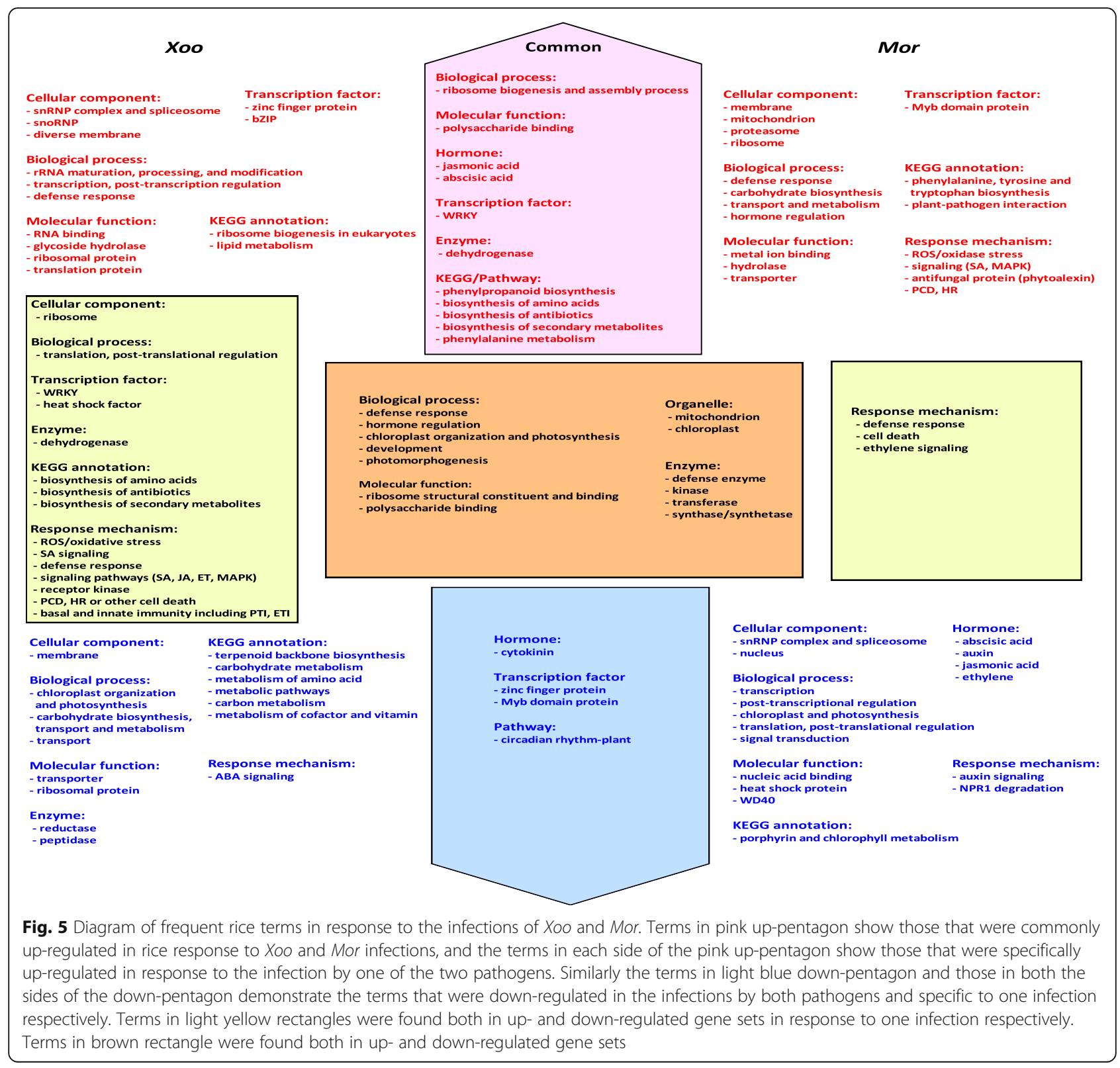


that genes involved in the following pathways were most frequently enriched in the up-regulated genes by Xoo: 'phenylpropanoid biosynthesis' (osa00940), 'biosynthesis of amino acids' (osa01230), 'biosynthesis of antibiotics' (osa01130), 'ribosome biogenesis in eukaryotes' (osa03008), and 'biosynthesis of secondary metabolites' (osa01110) pathways (Additional file 30: Table S27). In the down-regulated genes by Xoo, the most frequent pathways targeted were 'biosynthesis of secondary metabolites' (osa01110), 'metabolic pathways' (osa01100), 'biosynthesis of antibiotics' (osa01130), and 'carbon metabolism' (osa01200) (Additional file 31: Table S28).

To better outline the enrichment results of the KEGG targeted by the DEGs in rice induced by Xoo and Mor, all the pathways enriched were divided into eight categories (Table 8, Table 10). As shown in Table 8, disease resistance related pathways, carbohydrate metabolism, and genetic information processing were the top three frequently enriched categories in the up-regulated genes by Xoo; and in the down-regulated genes by Xoo, carbohydrate metabolism, disease resistance related pathways, and biosynthesis and metabolism of amino acids were observed to be the most frequently enriched pathways. Comparison of the pathways targeted by the genes induced by $\mathrm{Xoo}$ indicates that the pathways related to genetic information processing and lipid metabolism were more frequently enriched in the up-regulated genes, while the pathways involving metabolism of cofactors and vitamins were more frequently enriched in the down-regulated genes (Table 8).

Among the disease resistance related pathways, 'phenylpropanoid biosynthesis' (osa00940), 'biosynthesis of antibiotics' (osa01130), and 'phenylalanine metabolism' (osa00360) were the most frequent pathways activated

Table 8 The distribution of the enriched KEGG of the genes induced by $X_{O O}$ in the rice microarray data

\begin{tabular}{lll}
\hline Pathway category & $\begin{array}{l}\text { Frequency in the analyzed } \\
\text { samples }\end{array}$ \\
\cline { 2 - 3 } & Up-regulation & Down-regulation \\
\hline $\begin{array}{l}\text { Disease resistance related } \\
\text { pathways }\end{array}$ & 101 & 70 \\
$\begin{array}{l}\text { Carbohydrate metabolism } \\
\text { Genetic Information Processing }\end{array}$ & 79 & 76 \\
$\begin{array}{l}\text { Biosynthesis and metabolism } \\
\text { of amino acids }\end{array}$ & 75 & 14 \\
$\begin{array}{l}\text { Lipid metabolism } \\
\text { Biosynthesis of secondary }\end{array}$ & 30 & 69 \\
metabolites & 22 & 10 \\
$\begin{array}{l}\text { Metabolism of cofactors and } \\
\text { vitamins }\end{array}$ & 4 & 35 \\
Other pathways & 68 & 43 \\
\hline
\end{tabular}

by Xoo; however, 'biosynthesis of antibiotics' (osa01130), 'circadian rhythm-plant' (osa04712), and 'terpenoid backbone biosynthesis' (osa00900) were the most frequent pathways repressed by Xoo (Table 9).

We next analyzed the KEGG enrichment of the genes induced by Mor. This analysis led to a similar KEGG enrichment of the up-regulated genes by Mor to that of the genes activated by Xoo. As listed in Additional file 32: Table S29, 'biosynthesis of secondary metabolites' (osa01110), 'biosynthesis of amino acids' (osa01230), 'phenylpropanoid biosynthesis' (osa00940), and 'biosynthesis of antibiotics' (osa01130) were also frequently enriched in Mor-up-regulated genes. However, in the Mor-down-regulated genes, the frequent KEGG enrichment annotations were 'plant hormone signal transduction' (osa04075), 'circadian rhythm-plant' (osa04712), and 'porphyrin and chlorophyll metabolism' (osa00860)

Table 9 The distribution of the enriched KEGG pathways related to disease resistance of the genes induced by Xoo in the rice microarray data. Up-Reg: Up-regulation; Down-Reg: Downregulation

\begin{tabular}{|c|c|c|c|}
\hline \multirow{2}{*}{$\begin{array}{l}\text { Disease resistance related } \\
\text { pathways }\end{array}$} & \multirow[t]{2}{*}{ Reference } & \multicolumn{2}{|c|}{ Number of sample } \\
\hline & & Up-Reg & Down-Reg \\
\hline $\begin{array}{l}\text { Osa00940:Phenylpropanoid } \\
\text { biosynthesis }\end{array}$ & {$[25-28]$} & 16 & 3 \\
\hline $\begin{array}{l}\text { osa01130:Biosynthesis of } \\
\text { antibiotics }\end{array}$ & & 15 & 18 \\
\hline $\begin{array}{l}\text { osa00360:Phenylalanine } \\
\text { metabolism }\end{array}$ & [29-31] & 14 & 0 \\
\hline $\begin{array}{l}\text { osa00400:Phenylalanine, } \\
\text { tyrosine and tryptophan } \\
\text { biosynthesis }\end{array}$ & {$[32]$} & 11 & 0 \\
\hline $\begin{array}{l}\text { osa04075:Plant hormone } \\
\text { signal transduction }\end{array}$ & {$[21,23,33-37]$} & 10 & 5 \\
\hline $\begin{array}{l}\text { osa00945:Stilbenoid, } \\
\text { diarylheptanoid and gingerol } \\
\text { biosynthesis }\end{array}$ & {$[38-40]$} & 9 & 0 \\
\hline $\begin{array}{l}\text { osa03450:Non-homologous } \\
\text { end-joining }\end{array}$ & [41] & 8 & 0 \\
\hline $\begin{array}{l}\text { osa04712:Circadian } \\
\text { rhythm - plant }\end{array}$ & {$[42-44]$} & 7 & 16 \\
\hline $\begin{array}{l}\text { osa04626:Plant-pathogen } \\
\text { interaction }\end{array}$ & & 6 & 2 \\
\hline $\begin{array}{l}\text { osa00941:Flavonoid } \\
\text { biosynthesis }\end{array}$ & {$[45]$} & 5 & 3 \\
\hline $\begin{array}{l}\text { osa00900:Terpenoid } \\
\text { backbone biosynthesis }\end{array}$ & {$[46]$} & 0 & 12 \\
\hline $\begin{array}{l}\text { osa00908:Zeatin } \\
\text { biosynthesis }\end{array}$ & {$[47]$} & 0 & 7 \\
\hline $\begin{array}{l}\text { osa00480:Glutathione } \\
\text { metabolism }\end{array}$ & {$[48]$} & 0 & 2 \\
\hline $\begin{array}{l}\text { osa00909:Sesquiterpenoid } \\
\text { and triterpenoid biosynthesis }\end{array}$ & {$[49,50]$} & 0 & 2 \\
\hline
\end{tabular}


(Additional file 33: Table S30). Broad KEGG enrichment results indicated that disease resistance related pathways, biosynthesis and metabolism of amino acids, and carbohydrate metabolism categories were most frequently enriched in the up-regulated genes by Mor; while in the genes repressed by Mor, the most frequent enrichment categories of KEGG were disease resistance related pathways, genetic information processing, and biosynthesis and metabolism of amino acids (Table 10).

Further analysis showed that the most frequently activated disease resistance related pathway by Mor in rice was 'phenylalanine, tyrosine and tryptophan biosynthesis' (osa00400), followed by 'phenylalanine metabolism' (osa00360), 'phenylpropanoid biosynthesis' (osa00940), 'biosynthesis of antibiotics' (osa01130), and 'plant-pathogen interaction' (osa04626) (Table 11). In contrast, 'plant hormone signal transduction' (osa04075), and 'circadian rhythm-plant' (osa04712) were the most frequently repressed pathways related to disease resistance by Mor in rice (Table 11).

\section{Discussion}

Transcriptomic analysis is a powerful tool to reveal the interactions between host and pathogen [61-64]. In this study, we analyzed 35 pairs of samples from 69 pairs of Xoo- or Mor-infected rice microarray samples deposited in the GEO database. Some rice genes were identified to be frequently regulated by Xoo and Mor in various conditions. During the interactions between rice and these two pathogens, the pathogen attacks coincided with rice defenses. We separated the up-regulated genes and down-regulated genes by pathogens in rice, in other words, there was no gene overlap between them. GO, InterPro and KEGG annotations and enrichment

Table 10 The distribution of the enriched KEGG of the genes induced by Mor in the rice microarray data

\begin{tabular}{lll}
\hline Pathway category & \multicolumn{2}{l}{ Frequency in the analyzed samples } \\
\cline { 2 - 3 } & Up-regulation & Down-regulation \\
\hline $\begin{array}{l}\text { Disease resistance related } \\
\text { pathways }\end{array}$ & 38 & 17 \\
$\begin{array}{l}\text { Biosynthesis and metabolism } \\
\text { of amino acids }\end{array}$ & 27 & 9 \\
Carbohydrate metabolism & 25 & 8 \\
$\begin{array}{l}\text { Lipid metabolism } \\
\text { Biosynthesis of secondary }\end{array}$ & 11 & 2 \\
metabolites & 8 & 2 \\
Genetic information processing & 4 & 11 \\
$\begin{array}{l}\text { Metabolism of cofactors and } \\
\text { vitamins }\end{array}$ & 1 & 7 \\
Other pathways & 20 & 10 \\
\hline
\end{tabular}

Table 11 The distribution of the enriched KEGG pathways related to disease resistance of the genes induced by Mor in the rice microarray data. Up-Reg: Up-regulation; Down-Reg: Downregulation

\begin{tabular}{|c|c|c|c|}
\hline \multirow{2}{*}{$\begin{array}{l}\text { Disease resistance related } \\
\text { pathways }\end{array}$} & \multirow[t]{2}{*}{ Reference } & \multicolumn{2}{|c|}{ Number of sample } \\
\hline & & Up-Reg & Down-Reg \\
\hline $\begin{array}{l}\text { osa00400:Phenylalanine, } \\
\text { tyrosine and tryptophan } \\
\text { biosynthesis }\end{array}$ & {$[32]$} & 6 & 0 \\
\hline $\begin{array}{l}\text { osa00360:Phenylalanine } \\
\text { metabolism }\end{array}$ & [29-31] & 4 & 0 \\
\hline $\begin{array}{l}\text { osa00940:Phenylpropanoid } \\
\text { biosynthesis }\end{array}$ & [25-28] & 4 & 0 \\
\hline $\begin{array}{l}\text { osa01130:Biosynthesis of } \\
\text { antibiotics }\end{array}$ & & 4 & 1 \\
\hline $\begin{array}{l}\text { osa04626:Plant-pathogen } \\
\text { interaction }\end{array}$ & & 4 & 1 \\
\hline $\begin{array}{l}\text { osa00900:Terpenoid } \\
\text { backbone biosynthesis }\end{array}$ & {$[46]$} & 3 & 0 \\
\hline osa03050:Proteasome & {$[51,52]$} & 3 & 0 \\
\hline $\begin{array}{l}\text { osa00053:Ascorbate and } \\
\text { aldarate metabolism }\end{array}$ & {$[53,54]$} & 2 & 0 \\
\hline $\begin{array}{l}\text { osa00480:Glutathione } \\
\text { metabolism }\end{array}$ & {$[48]$} & 2 & 0 \\
\hline $\begin{array}{l}\text { osa00945:Stilbenoid, } \\
\text { diarylheptanoid and gingerol } \\
\text { biosynthesis }\end{array}$ & [38-40] & 2 & 0 \\
\hline $\begin{array}{l}\text { osa00941:Flavonoid } \\
\text { biosynthesis }\end{array}$ & {$[45]$} & 2 & 0 \\
\hline $\begin{array}{l}\text { osa04075:Plant hormone } \\
\text { signal transduction }\end{array}$ & {$[21,23,33-37]$} & 1 & 4 \\
\hline osa04144:Endocytosis & {$[55-57]$} & 1 & 0 \\
\hline $\begin{array}{l}\text { osa04712:Circadian } \\
\text { rhythm - plant }\end{array}$ & {$[42-44]$} & 0 & 3 \\
\hline $\begin{array}{l}\text { osa03015:mRNA } \\
\text { surveillance pathway }\end{array}$ & {$[58]$} & 0 & 2 \\
\hline $\begin{array}{l}\text { osa03022:Basal } \\
\text { transcription factors }\end{array}$ & & 0 & 2 \\
\hline osa03410:Base excision repair & & 0 & 1 \\
\hline osa03430:Mismatch repair & & 0 & 1 \\
\hline $\begin{array}{l}\text { osa04130:SNARE interactions } \\
\text { in vesicular transport }\end{array}$ & {$[59,60]$} & 0 & 1 \\
\hline $\begin{array}{l}\text { osa03450:Non-homologous } \\
\text { end-joining }\end{array}$ & {$[41]$} & 0 & 1 \\
\hline
\end{tabular}

analyses were performed respectively on the up- and down-regulated genes in each rice sample infected by Xoo or Mor. We further revealed the frequent GO, InterPro and KEGG annotations and enrichment results of rice genes regulated by Xoo and Mor.

Some studies have been carried out to investigate the responsive mechanisms in rice to the infections of Xoo and Mor in specific conditions. The roles of resistance genes were focused on in early studies on rice response 
to Xoo infection [12]. Recently, analyses of transcriptomic data revealed the detailed responses to Xoo and Mor infections in rice. It has been demonstrated that the transcriptional changes during the compatible interaction between rice and Mor were very similar to the changes of incompatible interaction; nevertheless, the changes were higher during the incompatible interaction [8]. In plants including rice, transcriptional reprogramming is a universal process during the infections of pathogens $[9,65,66]$. Our results indicate that the frequently regulated genes involved in basic biological processes from transcription to translation, and their regulation.

A number of researches reported the expression profiles of rice defense response genes [9, 67]. For example, chitinase activities were detected to play roles in rice resistance to Mor $[68,69]$. Our results show that the expected defense enzymes were the most frequent products of the regulated genes by Xoo and Mor (Fig. 2, Fig. 5, Additional file 12: Table S9, Additional file 11: S8. Additional file 16: S13. and Additional file 17: S14).

Genes related to secondary metabolism were observed to be up-regulated and significantly enriched in rice infected by Mor [8]. In Arabidopsis, metabolic pathways were observed to be frequently influenced by diverse pathogens [70]. The resistance to Mor was shown in wild rice plants to be involved in lipid metabolism, phenylpropanoid and diterpenoid metabolism [69]. During the interaction of a pair of rice near-isogenic lines (NILs) with $X o o$, phenylpropanoid biosynthesis was identified as the most conspicuous pathway [11]. In our analysis, KEGG enrichment indicated that 'phenylpropanoid biosynthesis' (osa00940) and 'biosynthesis of secondary metabolites' (osa01110) were observed to be two of the most frequently enriched pathways in the up-regulated genes by Xoo and Mor (Fig. 5, Additional file 30: Table S27 and Additional file 32: Table S29). However, 'biosynthesis of secondary metabolites' (osa01110) was also the most frequent pathway targeted by the down-regulated genes by Xoo (Additional file 31: Table S28). Our analysis further showed 'biosynthesis of antibiotics' (osa01130) and 'biosynthesis of amino acids' (osa01230) were another two of the pathways most frequently enriched by the up-regulated genes by Xoo and Mor (Fig. 5, Additional file 30: Table S27 and Additional file 32: Table S29).

Analysis of the DRR/DSR genes responsive to Xoo and Mor infections suggests that various disease resistance mechanisms were activated or repressed in rice. Among the mechanisms, defense response, signaling pathways, PCD, HR and other cell death, basal and innate immunity were the most eminent arenas that fight between rice and these two pathogens (Fig. 4, Additional file 1: Figure S1 and Additional file 2: Figure S2). It is worth noting that genes encoding antifungal proteins and related to the synthesis of phytoalexin were activated in rice after Mor but Xoo infection, suggesting that different mechanisms were triggered (Fig. 5 and Additional file 2: Figure S2).

WRKY transcription factors were again and again observed to be implicated in the rice resistance to Mor [8, $68,69]$. In our analysis, WRKY proteins (IPR003657) were the most frequently activated transcription factors by Mor (Table S26). The WRKY factors were also frequently up-regulated by Xoo (Fig. 5, Additional file 8: Table S5). In addition, the zinc finger domain proteins, and the Myb domain proteins were demonstrated to be the most significant factors with differential expressions in most samples infected by Xoo and Mor (Fig. 5, Additional file 8: Table S5 and Additional file 27: Table S24).

Signalings mediated by abscisic acid and cytokinin were revealed to be successively activated by Mor infection in rice [22]. Abscisic acid was also suggested being important in the rice (carrying $\mathrm{Xa} 7$ ) response to $\mathrm{Xoo}$ infection and high temperature stress [10]. However, our results indicate that the processes relative to abscisic acid may not only be frequently activated by the infections of Xoo and Mor (GO:0009737 response to abscisic acid; GO:0009738 abscisic acid-activated signaling pathway) (Fig. 3 and Fig. 5), but also be repressed by Mor infection (GO:0009738 abscisic acid-activated signaling pathway; GO:0009788 negative regulation of abscisic acid-activated signaling pathway) (Fig. 3b). In our results, processes with relation to cytokinin were strikingly and frequently repressed by Xoo and Mor infections (GO:0009735 response to cytokinin; GO:0009736 cytokinin-activated signaling pathway) (Fig. 3 and Fig. 5). Two pathways mediated by jasmonic acid and ethylene were demonstrated to be activated by Xoo and Mor infections [11, 68, 69]. Our results show that the processes relative to jasmonic acid were frequently activated in the Xoo- and Mor-infected rice (GO: 2000022 regulation of jasmonic acid mediated signaling pathway; GO:0009695 jasmonic acid biosynthetic process; GO:0009753 response to jasmonic acid) (Fig. 3 and Fig. 5), and they may be repressed by Mor infection (Fig. 3b and Fig. 5). The processes relative to ethylene (GO:0009693 ethylene biosynthetic process; GO: 0009723 response to ethylene; GO:0009873 ethyleneactivated signaling pathway) were also repressed in Morinfected rice (Fig. 3b).

Previous studies have shown that the mechanisms by which rice plants respond to the infections of Xoo and Mor are not quite identical or even completely opposite under different experimental systems and experimental conditions. Our results reveal which mechanisms are occurring with a relatively high probability.

We show that Os04g0650800 was most frequently activated by Xoo. This gene encodes the D-3- 
phosphoglycerate dehydrogenase 3 in chloroplast. It has been established that the phosphorylated pathway in plastidial glycolysis is one of three different serine biosynthesis pathways in plants, and 3-phosphoglycerate dehydrogenase (PGDH) is the first committed enzyme [71]. PGDH was revealed to be quantitatively the most important enzyme in maintaining serine homeostasis at the whole plant level [72]. Our result suggests that Os04g0650800 is likely a key gene in rice defense response and the activation of serine biosynthesis dependent on a phosphorylated pathway may be important in rice response to Xoo invasion.

As shown above, the genes responsive to $\mathrm{Xoo}$ and Mor infections may be up-regulated or down-regulated. Further experiments of molecular genetics are necessary to determine that the up- or down-regulated expressions of these genes are active or passive, and to reveal the significance of the genes with highly frequent expressions in response to the infections of these two pathogens. In this study, only six pairs of Mor-infected samples were retrieved and analyzed, therefore more extensive analyses are needed on the genes and mechanisms responsive to Mor infection in rice.

\section{Conclusions}

A robust set of genes has been defined in rice response to the infections of Xoo and Mor. Mitochondrion and chloroplast may be important organelles for rice response to Xoo and Mor infections. Processes with relation to cytokinin, jasmonic acid, and abscisic acid were most frequently operated by Xoo and Mor. A great number of enzymes were in rice favored to be manipulated by Xoo and Mor. Defense responses and diverse signaling pathways were indispensable among the responsive mechanisms of rice to Xoo and Mor. Pathways including phenylpropanoid biosynthesis, biosynthesis of antibiotics, phenylalanine metabolism, and biosynthesis of secondary metabolites were most frequently triggered by Xoo and Mor. Circadian rhythm-plant was the most frequent pathway repressed by Xoo and Mor.

\section{Materials and methods}

Retrieval and analysis of the microarray datasets of rice infected by $\mathrm{XoO}$ and Mor

The Xoo- and Mor-infected microarray data were collected from the Gene Expression Omnibus (GEO) database (https://www.ncbi.nlm.nih.gov/geo/) [73, 74]. Sixty-nine pairs (including control and treatment) of raw microarray data (.CEL) of rice in response to the infections of Xoo and Mor were obtained by SRA Toolkit. The microarray data included 15 series data sets consisting of 51 pairs of Xoo-infected rice samples and 18 pairs of Mor-infected rice samples. All the microarray experiments were conducted on the same Affymetrix platform (Rice Genome Array GPL2025). The Bioconductor package Simpleaffy was used for quality assessment [75]. GEOquery and limma $\mathrm{R}$ packages from GEO2R were used to identify the differential expression of all samples [76]. Poor quality samples were discarded and all the rest of samples (35 pairs of samples) were used to analyze the differentially expressed genes.

\section{Identification of the differentially expressed genes (DEGs) induced by Xoo and Mor infections}

A series of data generated by GEO2R were then evaluated and analyzed. The obtained $p$-values for multiple testing were corrected according to Benjamini and Hochberg procedure [77]. Probe IDs were converted to gene symbols according to the GPL2025 annotation file provided by GEO. To identify the DEGs, an adjusted $p$ value was used to filter genes with no differential expressions. By setting the threshold of adj. $P$-value $<0.05$, the genes with differential expression induced by Xoo and Mor were screened. Given that more than 30,000 genes were found in rice genome, and more than 1000 DEGs were indentified in many rice samples infected by pathogens, the infected samples with too few DEGs may be resulted from unknown experiment factors. Among the analyzed samples, 34 samples were found with more than 1000 DEGs, and a sample was found with nearly 1000 DEGs (989 DEGs). To avoid inaccurate results, samples with less than 989 DEGs were discarded. In the discarded 34 samples, no DEGs could be identified in 13 samples, DEGs with less than 200 genes were identified from nine samples, and the other samples were found with several hundred DEGs.

\section{Functional annotation and enrichment analysis for candidate DEGs induced by $\mathrm{Xoo}$ and Mor}

The DEGs were annotated through the Rice Genome Annotation Project (MSU, http://rice.plantbiology.msu. edu) [78]. For further InterPro annotation, homology searches were performed against the protein databases (Panther-12.0, PfamA-31.0, PRINTS-42.0, ProDom2006.1, SuperFamily-1.75, and TIGRFAM15.0), using the local InterProScan program (ver.5.31) [79, 80].

To reveal the potential function tendency of the above identified DEGs, GO enrichment was conducted through the DAVID tool (https://david.ncifcrf. gov/) $[81,82]$. And the enrichment analysis was deduced based on $p$-value $\leq 0.05$. Pathway analysis was also carried out through the DAVID tool to unravel the functional annotation of the identified DEGs, and the pathways with $p$-value $\leq 0.05$ were retrieved as significant enrichment [81, 82]. 


\section{Supplementary information}

Supplementary information accompanies this paper at https://doi.org/10. 1186/s12864-019-6438-y

Additional file 1: Figure S1. The number of unique and common differentially expressed genes (DEGs) present in at least three pairs of rice samples infected by Xoo and Mor. (A) Up-regulated genes; (B) Downregulated genes.

Additional file 2: Figure S2. Analysis on disease resistance mechanism of the up-regulated DRR/DSR proteins by Mor in rice.

Additional file 3: Figure S3. Analysis on disease resistance mechanism of the down-regulated DRR/DSR proteins by Mor in rice.

Additional file 4: Table S1. 69 rice microarray assays used in this study. Additional file 5: Table S2. The number of differentially expressed genes (DEGs) induced by Xoo and Mor.

Additional file 6: Table S3. The DEGs present in at least one sample infected by $X_{00}$ or Mor with pathogen-inducible cis-regulatory elements (PICES) in their promoters.

Additional file 7: Table S4. The DEGs present in at least three samples infected by Xoo or at least two samples infected by Mor with PICEs in their promoters.

Additional file 8: Table S5. The distribution of the cellular component ontology for the up-regulated genes by Xoo in the rice microarray data.

Additional file 9: Table S6. The distribution of the cellular component ontology for the down-regulated genes by Xoo in the rice microarray data. Additional file 10: Table S7. The distribution of the biological process ontology for the up-regulated genes by $X_{0 O}$ in the rice microarray data.

Additional file 11: Table S8. The distribution of the biological process ontology for the down-regulated genes by Xoo in the rice microarray data.

Additional file 12: Table S9. The distribution of the molecular functions of the up-regulated genes by $X_{0 O}$ in the rice microarray data.

Additional file 13: Table S10. The distribution of the molecular functions of the down-regulated genes by Xoo in the rice microarray data.

Additional file 14: Table S11. The distribution of the cellular component ontology for the up-regulated genes by Mor in the rice microarray data.

Additional file 15: Table S12. The distribution of the cellular component ontology for the down-regulated genes by Mor in the rice microarray data.

Additional file 16: Table S13. The distribution of the biological process ontology for the up-regulated genes by Mor in the rice microarray data.

Additional file 17: Table S14. The distribution of the biological process ontology for the down-regulated genes by Mor in the rice microarray data.

Additional file 18: Table S15. The distribution of the molecular functions of the up-regulated genes by Mor in the rice microarray data.

Additional file 19: Table S16. The distribution of the molecular functions of the down-regulated genes by Mor in the rice microarray data.

Additional file 20: Table S17. The distribution of the INTERPRO annotations of the up-regulated genes by $X_{0 O}$ in the rice microarray data.

Additional file 21: Table S18. The distribution of the INTERPRO annotations of the down-regulated genes by $X_{0 O}$ in the rice microarray data. Additional file 22: Table S19. The distribution of the INTERPRO annotations of the up-regulated genes by Mor in the rice microarray data.

Additional file 23: Table S20. The distribution of the INTERPRO annotations of the down-regulated genes by Mor in the rice microarray data.

Additional file 24: Table S21. The putative DRRG/DSRGs of the upregulated genes identified from the rice microarray data infected by $X_{0 o}$. Additional file 25: Table S22. The putative DRRG/DSRGs of the downregulated genes identified from the rice microarray data infected by Xoo.

Additional file 26: Table S23. The putative DRRG/DSRGs of the upregulated genes identified in the rice microarray data infected by Mor.
Additional file 27: Table S24. The putative DRRG/DSRGs of the downregulated genes identified in the rice microarray data infected by Mor. Additional file 28: Table S25. The putative differentially expressed transcription factors identified in the rice microarray data infected by Xoo

Additional file 29: Table S26. The putative differentially expressed transcription factors identified in the rice microarray data infected by Mor Additional file 30: Table S27. The distribution of KEGG annotations of the up-regulated genes by $X_{00}$ in the rice microarray data.

Additional file 31: Table S28. The distribution of KEGG annotations of the down-regulated genes by $X_{0 O}$ in the rice microarray data.

Additional file 32: Table S29. The distribution of KEGG annotations of the up-regulated genes by Mor in the rice microarray data.

Additional file 33: Table S30. The distribution of KEGG annotations of the down-regulated genes by Mor in the rice microarray data.

\section{Abbreviations}

ABA: Abscisic acid; DEGs: Differentially expressed genes; DRR/DSR: Disease resistance/susceptibility-related; ET: Ethylene; ETI: Effector-triggered immunity; GEO: Gene Expression Omnibus; GO: Gene Ontology; HR: Hypersensitive reaction; JA: Jasmonic acid; KEGG: Kyoto Encyclopedia of Genes and Genomes; Mor: Magnaporthe oryzae; PAMP: Pathogen-associated molecular pattern; PCD: Programmed cell death; PICEs: Pathogen-inducible cisregulatory elements; PRRs: Pattern recognition receptors; PTI: PAMP-triggered immunity; ROS: Reactive oxygen species; SA: Salicylic acid; Xoo: Xanthomonas oryzae pv. oryzae

\section{Acknowledgments}

Not applicable.

Authors' contributions

WK conceived and supervised the design of this study. LD analyzed the data. XX carried out the collation of partial data and forms, and made some Tables. WK wrote the manuscript. All authors read and approved the final version of the manuscript.

\section{Funding}

This study did not receive any grants provided by funding agencies in the public, commercial, or not-for-profit departments.

\section{Availability of data and materials}

The datasets supporting the conclusions of this article are included within the article and its additional files.

Ethics approval and consent to participate Not applicable.

\section{Consent for publication}

Not applicable.

\section{Competing interests}

The authors declare that they have no competing interests.

Received: 26 July 2019 Accepted: 29 December 2019

Published online: 06 January 2020

References

1. Boller T, He SY. Innate immunity in plants: an arms race between pattern recognition receptors in plants and effectors in microbial pathogens. Science. 2009;324(5928):742-4.

2. Dodds PN, Rathjen JP. Plant immunity: towards an integrated view of plantpathogen interactions. Nat Rev Genet. 2010;11(8):539-48.

3. Jones JD, Dangl JL. The plant immune system. Nature. 2006;444(7117): 323-9.

4. Chisholm ST, Coaker G, Day B, Staskawicz BJ. Host-microbe interactions: shaping the evolution of the plant immune response. Cell. 2006;124(4): 803-14.

5. Li B, Meng X, Shan L, He P. Transcriptional regulation of pattern-triggered immunity in plants. Cell Host Microbe. 2016;19(5):641-50. 
6. Maekawa T, Kufer TA, Schulze-Lefert P. NLR functions in plant and animal immune systems: so far and yet so close. Nat Immunol. 2011;12(9):818-26.

7. Gassmann W, Bhattacharjee S. Effector-triggered immunity signaling: from gene-for-gene pathways to protein-protein interaction networks. Mol PlantMicrobe Interact. 2012;25(7):862-8.

8. Wei T, Ou B, Li J, Zhao Y, Guo D, Zhu Y, et al. Transcriptional profiling of rice early response to Magnaporthe oryzae identified OsWRKYs as important regulators in rice blast resistance. PLoS One. 2013;8(3):e59720.

9. Sharma TR, Das A, Thakur S, Devanna BN, Singh PK, Jain P, et al. Oscillating transcriptome during rice-Magnaporthe interaction. Curr Issues Mol Biol. 2016;19:99-120.

10. Cohen SP, Liu H, Argueso CT, Pereira A, Vera Cruz C, Verdier V, et al. RNASeq analysis reveals insight into enhanced rice $\mathrm{X} a 7$-mediated bacterial blight resistance at high temperature. PLoS One. 2017;12(11):e0187625.

11. Tariq R, Wang C, Qin T, Xu F, Tang Y, Gao Y, et al. Comparative transcriptome profiling of rice near-isogenic line carrying Xa23 under infection of Xanthomonas oryzae pv. oryzae. Int J Mol Sci. 2018;19(3):717.

12. White FF, Yang B. Host and pathogen factors controlling the riceXanthomonas oryzae interaction. Plant Physiol. 2009;150(4):1677-86.

13. Liu J, Wang X, Mitchell T, Hu Y, Liu X, Dai L, et al. Recent progress and understanding of the molecular mechanisms of the rice-Magnaporthe oryzae interaction. Mol Plant Pathol. 2010;11(3):419-27.

14. Chen X, Ronald PC. Innate immunity in rice. Trends Plant Sci. 2011;16(8):451-9.

15. Shen X, Yuan B, Liu H, Li X, Xu C, Wang S. Opposite functions of a rice mitogen-activated protein kinase during the process of resistance against Xanthomonas oryzae. Plant J. 2010;64(1):86-99.

16. Shen X, Liu H, Yuan B, Li X, Xu C, Wang S. OsEDR1 negatively regulates rice bacterial resistance via activation of ethylene biosynthesis. Plant Cell Environ. 2011;34(2):179-91.

17. Deng H, Liu H, Li X, Xiao J, Wang S. A CCCH-type zinc finger nucleic acidbinding protein quantitatively confers resistance against rice bacterial blight disease. Plant Physiol. 2012;158(2):876-89.

18. Yamada S, Kano A, Tamaoki D, Miyamoto A, Shishido H, Miyoshi S, et al. Involvement of OsJAZ8 in jasmonate-induced resistance to bacterial blight in rice. Plant Cell Physiol. 2012;53(12):2060-72.

19. Xu J, Audenaert K, Hofte M, De Vleesschauwer D. Abscisic acid promotes susceptibility to the rice leaf blight pathogen Xanthomonas oryzae pv. oryzae by suppressing salicylic acid-mediated defenses. PLoS One. 2013;8(6):e67413.

20. Xu J, Zhou L, Venturi V, He YW, Kojima M, Sakakibari H, et al. Phytohormone-mediated interkingdom signaling shapes the outcome of rice-Xanthomonas oryzae pv oryzae interactions. BMC Plant Biol. 2015;15:10.

21. Yang DL, Yang $Y, H e Z$. Roles of plant hormones and their interplay in rice immunity. Mol Plant. 2013;6(3):675-85

22. Cao J, Yang C, Li L, Jiang L, Wu Y, Wu C, et al. Rice plasma membrane proteomics reveals Magnaporthe oryzae promotes susceptibility by sequential activation of host hormone signaling pathways. Mol PlantMicrobe Interact. 2016;29(11):902-13.

23. Muller M, Munne-Bosch S. Ethylene response factors: a key regulatory hub in hormone and stress signaling. Plant Physiol. 2015;169(1):32-41.

24. Kong W, Ding L, Cheng J, Wang B. Identification and expression analysis of genes with pathogen-inducible cis-regulatory elements in the promoter regions in Oryza sativa. Rice. 2018;11(1):52

25. Franke R, Hemm MR, Denault JW, Ruegger MO, Humphreys JM, Chapple C. Changes in secondary metabolism and deposition of an unusual lignin in the ref8 mutant of Arabidopsis. Plant J. 2002;30(1):47-59.

26. Shadle GL, Wesley SV, Korth KL, Chen F, Lamb C, Dixon RA. Phenylpropanoid compounds and disease resistance in transgenic tobacco with altered expression of L-phenylalanine ammonia-lyase. Phytochemistry. 2003;64(1):153-61.

27. El-kereamy A, El-sharkawy I, Ramamoorthy R, Taheri A, Errampalli D, Kumar $P$, et al. Prunus domestica pathogenesis-related protein-5 activates the defense response pathway and enhances the resistance to fungal infection. PLoS One. 2011;6(3):e17973.

28. Cass CL, Peraldi A, Dowd PF, Mottiar Y, Santoro N, Karlen SD, et al. Effects of PHENYLALANINE AMMONIA LYASE (PAL) knockdown on cell wall composition, biomass digestibility, and biotic and abiotic stress responses in Brachypodium. J Exp Bot. 2015;66(14):4317-35.

29. Shine MB, Yang JW, El-Habbak M, Nagyabhyru P, Fu DQ, Navarre D, et al. Cooperative functioning between phenylalanine ammonia lyase and isochorismate synthase activities contributes to salicylic acid biosynthesis in soybean. New Phytol. 2016;212(3):627-36.
30. Kim DS, Hwang BK. An important role of the pepper phenylalanine ammonia-lyase gene (PAL1) in salicylic acid-dependent signalling of the defence response to microbial pathogens. J Exp Bot. 2014;65(9):2295-306.

31. Chezem WR, Memon A, Li FS, Weng JK, Clay NK. SG2-type R2R3-MYB transcription factor MYB15 controls defense-induced lignification and basal immunity in Arabidopsis. Plant Cell. 2017;29(8):1907-26.

32. Powell JJ, Carere J, Fitzgerald TL, Stiller J, Covarelli L, Xu Q, et al. The Fusarium crown rot pathogen Fusarium pseudograminearum triggers a suite of transcriptional and metabolic changes in bread wheat (Triticum aestivum L.). Ann Bot. 2017;119(5):853-67.

33. Llorente F, Muskett P, Sanchez-Vallet A, Lopez G, Ramos B, Sanchez-Rodriguez $C$, et al. Repression of the auxin response pathway increases Arabidopsis susceptibility to necrotrophic fungi. Mol Plant. 2008;1(3):496-509.

34. Fan J, Hill L, Crooks C, Doerner P, Lamb C. Abscisic acid has a key role in modulating diverse plant-pathogen interactions. Plant Physiol. 2009;150(4): 1750-61.

35. Reusche M, Klaskova J, Thole K, Truskina J, Novak O, Janz D, et al. Stabilization of cytokinin levels enhances Arabidopsis resistance against Verticillium longisporum. Mol Plant-Microbe Interact. 2013;26(8):850-60.

36. Shi H, Yan H, Li J, Tang D. BSK1, a receptor-like cytoplasmic kinase, involved in both BR signaling and innate immunity in Arabidopsis. Plant Signal Behav. 2013;8(8):e24996.

37. Wang S, Wang S, Sun Q, Yang L, Zhu Y, Yuan Y, et al. A role of cytokinin transporter in Arabidopsis immunity. Mol Plant-Microbe Interact. 2017;30(4): 325-33.

38. Huang L, Zhang S, Singer SD, Yin X, Yang J, Wang Y, et al. Expression of the grape Vasts21 gene in Arabidopsis confers resistance to osmotic stress and biotrophic pathogens but not Botrytis cinerea. Front Plant Sci. 2016;7:1379.

39. Zeng W, Sun Z, Cai Z, Chen H, Lai Z, Yang S, et al. Proteomic analysis by iTRAQ-MRM of soybean resistance to Lamprosema Indicate. BMC Genomics. 2017;18(1):444.

40. Xu J, Li M, Jiao P, Tao H, Wei N, Ma F, et al. Dynamic transcription profiles of "Qinguan" apple (Malus x domestica) leaves in response to Marssonina coronaria inoculation. Front Plant Sci. 2015;6:842

41. Richter KS, Jeske H. KU80, a key factor for non-homologous end-joining, retards geminivirus multiplication. J Gen Virol. 2015;96(9):2913-8.

42. Sauerbrunn N, Schlaich NL. PCC1: a merging point for pathogen defence and circadian signalling in Arabidopsis. Planta. 2004:218(4):552-61.

43. Griebel T, Zeier J. Light regulation and daytime dependency of inducible plant defenses in Arabidopsis: phytochrome signaling controls systemic acquired resistance rather than local defense. Plant Physiol. 2008;147(2):790-801.

44. Fu S, Shao J, Zhou C, Hartung JS. Transcriptome analysis of sweet orange trees infected with 'Candidatus Liberibacter asiaticus' and two strains of Citrus Tristeza virus. BMC Genomics. 2016;17:349.

45. Pasold S, Siegel I, Seidel C, Ludwig-Muller J. Flavonoid accumulation in Arabidopsis thaliana root galls caused by the obligate biotrophic pathogen Plasmodiophora brassicae. Mol Plant Pathol. 2010;11(4):545-62.

46. Lange BM. The evolution of plant secretory structures and emergence of terpenoid chemical diversity. Annu Rev Plant Biol. 2015;66(1):139-59.

47. Testone G, Bruno L, Condello E, Chiappetta A, Bruno A, Mele G, et al. Peach Prunus persica (L.) Batsch] KNOPE1, a class 1 KNOX orthologue to Arabidopsis BREVIPEDICELLUS/KNAT1, is misexpressed during hyperplasia of leaf curl disease. J Exp Bot. 2008:59(2):389-402

48. Parisy V, Poinssot B, Owsianowski L, Buchala A, Glazebrook J, Mauch F. Identification of PAD2 as a gamma-glutamylcysteine synthetase highlights the importance of glutathione in disease resistance of Arabidopsis. Plant J. 2007:49(1):159-72

49. Yin L, Qu J, Deng S, Liu S, Lu J, Zhang Y. Phytohormone and genome variations in Vitis amurensis resistant to downy mildew. Genome. 2017; 60(10):791-6.

50. Chen Y, Dong J, Bennetzen JL, Zhong M, Yang J, Zhang J, et al. Integrating transcriptome and microRNA analysis identifies genes and microRNAs for AHO-induced systemic acquired resistance in $\mathrm{N}$. tabacum. Sci Rep. 2017:7(1):12504

51. Copeland C, Woloshen V, Huang Y, Li X. AtCDC48A is involved in the turnover of an NLR immune receptor. Plant J. 2016;88(2):294-305.

52. Yao C, Wu Y, Nie H, Tang D. RPN1a, a $26 \mathrm{~S}$ proteasome subunit, is required for innate immunity in Arabidopsis. Plant J. 2012;71(6):1015-28.

53. Grosskinsky DK, Koffler BE, Roitsch T, Maier R, Zechmann B. Compartmentspecific antioxidative defense in Arabidopsis against virulent and avirulent Pseudomonas syringae. Phytopathology. 2012;102(7):662-73. 
54. Botanga CJ, Bethke G, Chen Z, Gallie DR, Fiehn O, Glazebrook J. Metabolite profiling of Arabidopsis inoculated with Alternaria brassicicola reveals that ascorbate reduces disease severity. Mol Plant-Microbe Interact. 2012;25(12):1628-38.

55. Hatsugai N, Hillmer R, Yamaoka S, Hara-Nishimura I, Katagiri F. The mu subunit of Arabidopsis adaptor protein-2 is involved in effector-triggered immunity mediated by membrane-localized resistance proteins. Mol PlantMicrobe Interact. 2016;29(5):345-51.

56. Kawchuk LM, Hachey J, Lynch DR, Kulcsar F, van Rooijen G, Waterer DR, et al. Tomato Ve disease resistance genes encode cell surface-like receptors. Proc Natl Acad Sci U S A. 2001;98(11):6511-5.

57. Ron M, Avni A. The receptor for the fungal elicitor ethylene-inducing xylanase is a member of a resistance-like gene family in tomato. Plant Cell. 2004;16(6):1604-15.

58. Gloggnitzer J, Akimcheva S, Srinivasan A, Kusenda B, Riehs N, Stampfl H, et al. Nonsense-mediated mRNA decay modulates immune receptor levels to regulate plant antibacterial defense. Cell Host Microbe. 2014;16(3):376-90.

59. Sugano S, Hayashi N, Kawagoe Y, Mochizuki S, Inoue H, Mori M, et al. Rice OsVAMP714, a membrane-trafficking protein localized to the chloroplast and vacuolar membrane, is involved in resistance to rice blast disease. Plant Mol Biol. 2016:91(1-2):81-95.

60. Acevedo-Garcia J, Collins NC, Ahmadinejad N, Ma L, Houben A, Bednarek P, et al. Fine mapping and chromosome walking towards the Rorl locus in barley (Hordeum vulgare L.). Theor Appl Genet. 2013;126(12):2969-82.

61. Becker MG, Haddadi P, Wan J, Adam L, Walker P, Larkan NJ, et al. Transcriptome analysis of R/m2-mediated host immunity in the Brassica napus-Leptosphaeria maculans pathosystem. Mol Plant-Microbe Interact. 2019:32(8):1001-12.

62. Karmakar K, Kundu A, Rizvi AZ, Dubois E, Severac D, Czernic P, et al. Transcriptomic analysis with the progress of symbiosis in 'crack-entry' legume Arachis hypogaea highlights its contrast with 'infection thread' adapted legumes. Mol Plant-Microbe Interact. 2019;32(3):271-85.

63. Yu D, Fang Y, Tang C, Klosterman SJ, Tian C, Wang Y. Genomewide transcriptome profiles reveal how bacillus subtilis lipopeptides inhibit microsclerotia formation in Verticillium dahliae. Mol Plant-Microbe Interact. 2019;32(5):622-34

64. Zhao C, Wang H, Lu Y, Hu J, Qu L, Li Z, et al. Deep sequencing reveals early reprogramming of Arabidopsis root transcriptomes upon Ralstonia solanacearum infection. Mol Plant-Microbe Interact. 2019;32(7):813-27.

65. Katagiri F. A global view of defense gene expression regulation--a highly interconnected signaling network. Curr Opin Plant Biol. 2004;7(5):506-11.

66. Eulgem T. Regulation of the Arabidopsis defense transcriptome. Trends Plant Sci. 2005;10(2):71-8

67. Vergne E, Ballini E, Marques S, Sidi Mammar B, Droc G, Gaillard S, et al. Early and specific gene expression triggered by rice resistance gene Pi33 in response to infection by ACE1 avirulent blast fungus. New Phytol. 2007;174(1):159-71.

68. Jain P, Singh PK, Kapoor R, Khanna A, Solanke AU, Krishnan SG, et al. Understanding host-pathogen interactions with expression profiling of NILS carrying rice-blast resistance Pi9 gene. Front Plant Sci. 2017;8:93.

69. Tian L, Shi S, Nasir F, Chang C, Li W, Tran LP, et al. Comparative analysis of the root transcriptomes of cultivated and wild rice varieties in response to Magnaporthe oryzae infection revealed both common and species-specific pathogen responses. Rice. 2018;11(1):26

70. Jiang Z, He F, Zhang Z. Large-scale transcriptome analysis reveals Arabidopsis metabolic pathways are frequently influenced by different pathogens. Plant Mol Biol. 2017;94(4-5):453-67.

71. Cascales-Minana B, Munoz-Bertomeu J, Flores-Tornero M, Anoman AD, Pertusa J, Alaiz M, et al. The phosphorylated pathway of serine biosynthesis is essential both for male gametophyte and embryo development and for root growth in Arabidopsis. Plant Cell. 2013;25(6):2084-101.

72. Toujani W, Munoz-Bertomeu J, Flores-Tornero M, Rosa-Tellez S, Anoman $A D$, Alseekh $S$, et al. Functional characterization of the plastidial 3phosphoglycerate dehydrogenase family in Arabidopsis. Plant Physiol. 2013;163(3):1164-78.

73. Edgar R, Domrachev M, Lash AE. Gene expression omnibus: NCBI gene expression and hybridization array data repository. Nucleic Acids Res. 2002; 30(1):207-10.

74. Barrett T, Wilhite SE, Ledoux P, Evangelista C, Kim IF, Tomashevsky M, et al. $\mathrm{NCBI}$ GEO: archive for functional genomics data sets--update. Nucleic Acids Res. 2013:41(Database issue):D991-5.
75. Wilson CL, Miller CJ. Simpleaffy: a BioConductor package for Affymetrix quality control and data analysis. Bioinformatics. 2005;21(18):3683-5.

76. Sean D, Meltzer PS. GEOquery: a bridge between the gene expression omnibus (GEO) and BioConductor. Bioinformatics. 2007;23(14):1846-7.

77. Benjamini Y, Hochberg Y. Controlling the false discovery rate: a practical and powerful approach to multiple testing. J R Stat Soc Ser B Methodol. 1995:57(1):289-300

78. Kawahara Y, de la Bastide M, Hamilton JP, Kanamori H, McCombie WR, Ouyang $\mathrm{S}$, et al. Improvement of the Oryza sativa Nipponbare reference genome using next generation sequence and optical map data. Rice. 2013;6(1):4

79. Jones P, Binns D, Chang H-Y, Fraser M, Li W, McAnulla C, et al. InterProScan 5 genome-scale protein function classification. Bioinformatics. 2014;30(9):1236-40.

80. Finn RD, Attwood TK, Babbitt PC, Bateman A, Bork P, Bridge AJ, et al. InterPro in 2017-beyond protein family and domain annotations. Nucleic Acids Res. 2017:45(D1):D190-9.

81. Huang DW, Sherman BT, Lempicki RA. Bioinformatics enrichment tools: paths toward the comprehensive functional analysis of large gene lists. Nucleic Acids Res. 2009;37(1):1-13.

82. Huang DW, Sherman BT, Lempicki RA. Systematic and integrative analysis of large gene lists using DAVID bioinformatics resources. Nat Protoc. 2009:4(1):44-57.

\section{Publisher's Note}

Springer Nature remains neutral with regard to jurisdictional claims in published maps and institutional affiliations.

\section{Ready to submit your research? Choose BMC and benefit from:}

- fast, convenient online submission

- thorough peer review by experienced researchers in your field

- rapid publication on acceptance

- support for research data, including large and complex data types

- gold Open Access which fosters wider collaboration and increased citations

- maximum visibility for your research: over $100 \mathrm{M}$ website views per year

At $\mathrm{BMC}$, research is always in progress.

Learn more biomedcentral.com/submissions 